\title{
Ameliorative Effect of Vanillic Acid on Serum Bilirubin, Chronotropic and Dromotropic Properties in the Cholestasis-Induced Model Rats
}

\author{
Narges Atefipour ${ }^{1}$, Mahin Dianat ${ }^{2}$, Mohammad Badavi $^{2}$, Alireza Sarkaki ${ }^{2}$
}

${ }^{1}$ M.Sc. of Physiology, Department of Physiology and Physiology Research Center, Faculty of Medicine, Ahvaz Jundishapur University of Medical Sciences, Ahvaz, Iran

${ }^{2}$ Ph.D. of Physiology, Faculty Member, Physiology Research Center and Department of Physiology, Faculty of Medicine, Ahvaz Jundishapur University of Medical Sciences, Ahvaz, Iran

\section{Type of article: Original}

\begin{abstract}
Introduction: The liver modulates several important roles, such as metabolism and liver cirrhosis, which have several cardiovascular problems. Due to preservative role of antioxidant agents in cardiovascular disease, consequently, many of them are applied as medicinal plants in traditional medicine. Vanillic acid (VA), as an antioxidant agent, has a principal preservative role on some diseases. In this study, the effect of vanillic acid was examined on heart rate (as chronotropic property), P-R interval (as dromotropic property), and serum bilirubin in cholestasis-induced model rats.

Methods: In this study, 32 male Sprague-Dawley rats weighing 200-250 g were allocated into four groups, and each group contained eight rats as follows: Control (normal saline, $1 \mathrm{ml} / \mathrm{kg}$, gavage, daily for 4 weeks), cirrhotic (normal saline, $1 \mathrm{ml} / \mathrm{kg}$, gavage, daily for 4 weeks), vanillic acid (10 mg/kg, gavage, daily for 4 weeks), cirrhotic treated with vanillic acid (10 mg/kg, gavage, daily for 4 weeks). Chronic biliary cirrhosis was induced in cirrhotic groups by four weeks Bile Duct Ligation (BDL). At the first day and four weeks after surgery, the animals were anesthetized, electrocardiograms were recorded (lead II), and chronotropic and dromotropic properties (HR and PR interval) were investigated. At the end of experimental duration, the animals were anesthetized, and blood samples were taken to measure serum bilirubin. The results were analyzed using t-test and one-way ANOVA by SPSS software, version 22.

Results: After induced of BDL, the results presented that laboratory parameter (bilirubin) in the cirrhotic group significantly increased compared to the control group. The P-R interval was reduced in the cirrhotic group compared to the control group, and there was no significant difference between heart rate in all groups. Bilirubin were reduced in cirrhotic groups treated with vanillic acid (VA) compared to cirrhotic group and also administration of VA in the cirrhotic treated with VA increased dromotropic property in comparison with the cirrhotic group.

Conclusion: According to the results obtained in this study, preventing elevated bilirubin and increase dromotropic property in cirrhotic group taking the VA suggested that the consumption of vanillic acid as an antioxidant can be effective in the prevention of liver diseases.
\end{abstract}

Keywords: vanillic acid, biliary cirrhosis, bilirubin, chronotropic, dromotropic, rat

\section{Introduction}

As the liver is the largest organ in the body and regulates many important body functions, such as metabolism, its effect on detoxification of hepatotoxicants also is an important function to prevent the hepatic hurt (1). Hepatic cirrhosis influences hundreds of millions of patients throughout the world. Liver cirrhosis is the final stage of diverse chronic liver disease (2), and whenever the scar tissue around the bile ducts is fabricated, this type of

\section{Corresponding author:}

Dr. Mahin Dianat, Physiology Research Center and Department of Physiology, Faculty of Medicine, Ahvaz Jundishapur University of Medical Sciences, Ahvaz, Iran.

Tel: +98.9163110437, Fax: +98.6133337370, Email: dianat@ajums.ac.ir

Received: October 02, 2015, Accepted: December 10, 2016, Published: May 2016

iThenticate screening: December 12, 2015, English editing: March 26, 2016, Quality control: April 10, 2016

(C) 2016 The Authors. This is an open access article under the terms of the Creative Commons Attribution-NonCommercialNoDerivs License, which permits use and distribution in any medium, provided the original work is properly cited, the use is non-commercial and no modifications or adaptations are made. 
cirrhosis is called biliary cirrhosis (3). Primary biliary cirrhosis (PBC) is a chronic, advanced autoimmune cholestatic liver disease that impacts the condition of life and is associated with increased mortality. PBC is determined by lymphocytic cholangitis and intralobular bile duct demolition leading to expansion of fibrosis, cirrhosis, and liver failure (4). Bile Duct Ligation (BDL) is an experimental model in animals, such as rats, that in this model, biliary fibrosis occurs and progresses rapidly. The initial stages in the BDL model are illustrated by acute cholestasis, as inflammation and oxidative stress carry out important roles (5).

Herbal medicines or traditional medicines with their therapeutic effects and preventive functions in multiple diseases are invaluable. Due to low side effects of the pharmaceutical plants, in traditional medicine, they have been used as substitutes for chemical drugs (6). Vanillin (4-hydroxy-3-methoxybenzaldehyde), white or yellow crystals, is a general non-toxic food's natural additives, and gives the odor and taste to vanilla food flavor. Vanillin, a combination widely used in foods, drugs, drinks, and cosmetics, has such multifold function as anti-metastatic (7), anti-melanogenesis (8) and anti-angiogenesis effects (9). Vanillin is transformed in the liver to a phenolic acid component (vanillic acid), 3-methoxy-4-hydroxy benzoic acid. Vanillic acid is excreted in the urine mostly in conjugated metabolite and as the free metabolite $(10,11)$. Commutation of nutritional vanillin to the vanillic acid (VA), as major urinary metabolite, has been corroborated in people and in rats (10-12). Vanillic acid (VA) and 3, 4dihydroxy benzoic acid (3, 4 diHB), two analogues of 4HB, that transport either a methoxyl or a hydroxyl group in position 5 of the ring (13). Vanillic acid (VA), a benzoic acid derived used as a consequential taste and aroma agent, is an oxidized form of vanillin (14). Vanillic acid is one of the Phenollic acids that were recognized in multitude plants, such as C. murale (15), Melilotus messanensis (16), Juglans regia L. (17), and orchard grass (18). Vanillic acid can be administrated as a natural antioxidant instead of synthetic ones which have a toxic potential (17). Multiple assays of the antioxidative properties of vanillin, vanillic acid and ethyl vanillin was shown the supremacy of antioxidative activity and radical-scavenging of vanillic acid (19). Vanillic acid has been shown to have considerable shielding effects on cardiac troponins, lipid peroxidation, antioxidant system, expressions of tumor necrosis factor-alpha gene, interleukin- 6 and interleukin- 1 beta, electrocardiogram, and also biochemical parameters in the hearts of isoproterenol-induced cardiotoxic rats $(20,21)$. Considering the ameliorative effect of vanillic acid on some cardiac parameters motivated us to consider the effect of laboratory parameter (serum bilirubin), P-R interval (as dremotropic property) and heart rate (as chronotropic property) in biliary cirrhosis induced by bile duct ligation (BDL) in rats.

\section{Material and Methods}

\subsection{Study design and setting}

This experimental study was conducted in 2014-2015 at the Physiology Research Center of the Ahvaz Jundishapur University of Medical Sciences in Ahvaz, Iran. Thirty-two Sprague-Dawley rats were selected according to previous studies.

\subsection{Chemicals}

Vanillic acid (sigma), normal saline (N/S), Ketamine hydrochloride and Xylazine (Alfasan Co, Woderen-Holland).

\subsection{Animals}

In this study, 32 male Sprague-Dawley rats (prepared from animal's house, Ahvaz Jundishapur University of Medical Sciences) weighing 200-250 g were used. The animals were kept in separated cages under standard laboratory conditions (temperature of $23 \pm 2{ }^{\circ} \mathrm{C}$ and $12: 12 \mathrm{~h}$ light-dark cycle) with free accessibility to food and water. The examination protocol was approved by local research and ethics committees at Ahvaz Jundishapur University of Medical Sciences.

\subsection{Experimental Design}

The animals were assigned randomly into four groups ( $\mathrm{n}=8$ for each group) as follows: Sham, Cirrhosis, Vanillic acid and Cirrhosis treated with Vanillic acid. In the control group, the rats underwent surgery then the common bile duct was only dissected from the circumambient tissue and was permitted to recover in separate cage with free accessibility to food and water. Biliary cirrhosis in animals (extrahepatic cholestasis) was induced by 28 days (chronic) double BDL. Each rat was anesthetized using $50 \mathrm{mg} / \mathrm{kg}$ ketamine and $10 \mathrm{mg} / \mathrm{kg}$ xylazine hydrochloride (22) and after a midline abdominal cutting and recognizing the common bile duct; a double ligature was made with $3 / 0$ silk thread (23). In the cirrhotic treated with vanillic acid groups, vanillic acid was administrated diurnally (10 $\mathrm{mg} / \mathrm{kg}$ ) by gavage (24) for a period of 28 days, and other groups received a analogous volume of normal saline (in control and cirrhotic groups) or vanillic acid $(10 \mathrm{mg} / \mathrm{kg})$ by gavage $(25,26)$. 


\subsection{P-R interval and Heart rate recording}

The animals were operated under anesthesia with a combination of xylazine $(10 \mathrm{mg} / \mathrm{kg})$ and ketamine $(50 \mathrm{mg} / \mathrm{kg})$ via intraperitoneal (ip) path (27). Lead II electrocardiogram (ECG) was seized by Bio Amp and monitored by a Power lab system (AD-Instruments, Australia). P-R interval (as a dromotropic property) and HR (as a chronotropic property) was computed from ECG recording on the first day and 28 days after performance.

\subsection{Bilirubin Analysis}

After opening the chest, blood samples accumulated for measurement serum bilirubin in plasma as a marker to show the incidence cholestasis (28). Total and conjugated (direct) bilirubin tested with kit (Pars Azmoon Co., Iran) and were measured by colorimetric method using an auto analyzer (BT3000).

\subsection{Statistical analysis}

The comparison between groups statistically analyzed using one-way analyses of variance (ANOVA) followed by LSD (Least Significant Difference) as post hoc test. The data obtained for HR and P-R interval were analyzed using the paired t-test. The data were analyzed using IBM-SPSS version 22 and calculated as mean \pm standard error of the mean (SEM), and $p<0.05$ was considered to be statistically significant.

\section{Results}

\subsection{Effect of VA on laboratory parameter (bilirubin)}

The amounts of conjugated (direct) and total bilirubin levels in all groups are provided in Table 1. There was shown that the amount of direct and total bilirubin not only in cirrhotic group and in cirrhotic group received VA was significantly higher than the control group $(\mathrm{p}<0.001)$, but also significant difference between the amount of total and direct bilirubin levels in cirrhotic and cirrhotic received VA $(10 \mathrm{mg} / \mathrm{kg} / \mathrm{day}, 28$ days) groups was observed $(\mathrm{p}<$ 0.001 and $\mathrm{p}<0.05$, respectively). There was no significant difference between the bilirubin levels in the control and VA groups.

Table 1. Comparison of P-R interval, HR and bilirubin level (direct and total) in different groups, 28 days after BDL in rat

\begin{tabular}{|l|l|l|l|l|l|l|}
\hline \multirow{2}{*}{ Groups } & \multicolumn{2}{l|}{ Bilirubin level (mg/dl) } & \multicolumn{2}{l|}{ P-R Interval (ms) } & \multicolumn{2}{l|}{ HR (beats/min) } \\
\cline { 2 - 7 } & Direct & Total & First day & Last day & First day & Last day \\
\hline Control (Saline, $1 \mathrm{mg} / \mathrm{kg} /$ day) & $0.09 \pm 0.001$ & $0.14 \pm 0.001$ & $55 \pm 6$ & $55 \pm 6$ & $295 \pm 20$ & $295 \pm 20$ \\
\hline Vanillic acid (10 mg/kg/day) & $0.1 \pm 0.001$ & $0.11 \pm 0.06$ & $51 \pm 0.3$ & $59 \pm 2$ & $290 \pm 15$ & $290 \pm 15$ \\
\hline Cirrhosis (Saline, $1 \mathrm{mg} / \mathrm{kg} /$ day) & $3 \pm 0.6$ & $7 \pm 1.7$ & $53 \pm 3$ & $45 \pm 0.4$ & $290 \pm 12$ & $290 \pm 12$ \\
\hline $\begin{array}{l}\text { Cirrhosis+Vanillic acid (10 } \\
\mathrm{mg} / \mathrm{kg} / \text { day) }\end{array}$ & $1.8 \pm 0.4$ & $3 \pm 0.6$ & $50 \pm 0.5$ & $49 \pm 1$ & $300 \pm 14$ & $300 \pm 14$ \\
\hline
\end{tabular}

\subsection{Dromotropic property in all groups}

Four weeks after BDL induction, comparison of P-R interval showed that, there is a significant decrease in cirrhotic group (Table 1, $\mathrm{p}<0.05)$ and there was a significant increase in vanillic group $(\mathrm{p}<0.05)$. Also, the effect of administration of VA on P-R interval showed that P-R interval was increased in cirrhotic treated by VA in comparison to cirrhotic group (Table 1).

\section{3. $H R$}

Four weeks after BDL induction, HR was significantly reduced in the animals that received VA (Table $1, p<0.05$ ), however, HR did not show a significant difference in the other groups.

\section{Discussion}

In this study, the effect of vanillic acid (VA) was determined on P-R interval (as dromotropic property), heart rate (as chronotropic property), and laboratory parameter (conjugated and total bilirubin levels) in cirrhotic rats. VA has an anti-inflammatory, antioxidant, and free radical scavenging properties, which administrated four weeks to control cardiovascular complications and laboratory parameters caused by cirrhosis. In Prince et al.'s study, the impressive dose of vanillic acid was $(10 \mathrm{mg} / \mathrm{kg})$; accordingly, we resolved to use $10 \mathrm{mg} / \mathrm{kg}$ in our study (21). A well-known model to construct cirrhosis in animals is Bile Duct Ligation (BDL) (29). In this study, BDL chronically induced liver cirrhosis in groups. This effect was reflected by a considerable increase in serum bilirubin levels. Bilirubin in the cirrhotic group showed a significant increase in comparison with the control group. The amount of serum bilirubin level demonstrated a significant change in cirrhosis group treated vanillic acid. BDL induced cirrhosis 
enhanced liver damage markers. Chronic BDL significantly increases most of plasma and hepatic cytokine levels (28). Cirrhotic groups demonstrated significant decrease in P-R interval after four weeks of BDL compared to control group. Moreover P-R interval in VA-treated group was increased significantly. It seems that vanillic acid therapy prevented the decrease in P-R interval. Bearing in mind the positive impact of VA to avoid further changes in the P-R interval in this study, it seems that VA has a useful effect on cardiac complications followed by cirrhosis and acts as an antiarrhythmic agent (30). As reported in a previous study, activation of non-enzymatic materials, such as glutathione, was increased by vanillic acid consumption and acts as a strong agent to scavenging hydroxyl radicals, reactive oxygen species (ROS), and superoxide anions (19). These effects may be related to the phenolic properties of VA (31), which removed damaging materials, such as free radicals and did not permit the release of ROS. During arrhythmia, free radicals cause damage to the sarcoplasmic membrane and increased intracellular calcium, so caused to early and delay after depolarization (32). A previous study showed that vanillic acid increased activation of glutathione peroxidase, superoxide dismutase and catalase and as a scavenger, removed free radicals and therefore, vanillic acid exerts protective effects against the damage caused by free radicals (21). These findings indicate that vanillic acid as a powerful phenolic compounds that derivative from vanillin, Probably binds with betaadrenergic receptors and they prevent from increasing heart rate which caused by beta-adrenergic receptors stimulating. Beta-blockers also bind to beta-adrenoceptors in cardiac conducting system. Therefore, beta-blockers cause decreases in relaxation rate and conduction velocity (33). However, further research is necessary to demonstrate the mentioned hypothesis. These results are consistent with our findings for vanillic acid $10 \mathrm{mg} / \mathrm{kg}$ (34). Therefore, it seems that protective effects of VA probably are mediated via free radicals scavenging, antioxidant, blocks channels or inhibition of microsomal enzymes activities and has an antiarrhythmic property.

\section{Conclusions}

In this study, significant decrease in bilirubin and increased P-R interval in cirrhotic group treated by vanillic acid was shown. This finding demonstrated the ameliorative effect of the consumption of vanillic acid in the cholestasisinduced model rats. This study suggests that vanillic acid, as an antioxidant agent, may be useful in cirrhotic patients.

\section{Acknowledgments:}

This study is a part of MSc. thesis of Mrs. Narges Atefipour, MSc. student of Ahvaz Jundishapur University of Medical Sciences. The authors gratefully acknowledge the help and financial support of the Physiology Research Center of Ahvaz Jundishapur University of Medical Sciences (grant No: APRC-93-10).

\section{Conflict of Interest:}

There is no conflict of interest to be declared.

\section{Authors' contributions:}

All authors contributed to this project and article equally. All authors read and approved the final manuscript.

\section{References:}

1) Giannelli G, Quaranta V, Antonaci S. Tissue remodelling in liver diseases. Histol Histopathol. 2003; 18: 1267-74. PMID: 12973693.

2) Al-Attar AM, Shawush NA. Influence of olive and rosemary leaves extracts on chemically induced liver cirrhosis in male rats. Saudi J Biol Sci. 2015; 22(2): 157-63. doi: 10.1016/j.sjbs.2014.08.005, PMID: 25737646, PMCID: PMC4336450.

3) Braunwald E, Fauci AS, Kasper DL, Hauser SL, Longo DL, Jameson JL, et al. Harrison,s Principles of Internal Medicine, 17th Edition. McGraw-Hill, New York. 2008. 12-4.

4) Hirschfield GM, Mason A, Luketic V, Lindor K, Gordon SC, Mayo M, et al. Efficacy of Obeticholic acid in patients with primary biliary cirrhosis and inadequate response to ursodeoxycholic acid. Gastroenterology . 2015; 148(4): 751-61.e8. doi: 10.1053/j.gastro.2014.12.005, PMID: 25500425.

5) Lotkova H, Stankova P, Rousar T, Kučera O, Kohoutek L, Mičuda S, et al. Deteriorating effect of fluvastatin on the cholestatic liver injury indused by bile duct ligation in rats. Gen Physiol Biophys. 2011; 30: 66-74. doi: 10.4149/gpb_2011_01_66, PMID: 21460414.

6) Scartezzini P, Speroni E. Riview on some plants of Indian traditional medicine with antioxidant activity. J Ethnopharmacol. 2000; 71(1): 23-43. doi: 10.1016/S0378-8741(00)00213-0, PMID: 10904144. 
7) Lirdprapamongkol K, Sakurai H, Kawasaki N, Choo MK, Saitoh Y, Aozuka Y, et al. Vanillin suppresses in vitro invasion and in vivo metastasis of mouse breast cancer cells. Eur J Pharm Sci. 2005; 25(1): 57-65. doi: 10.1016/j.ejps.2005.01.015, PMID: 15854801.

8) Chou TH, Ding HY, Hung WJ, Liang CH. Antioxidative characteristics and inhibition of alphamelanocyte-stimulating hormone-stimulated melanogenesis of vanillin and vanillic acid from Origanum vulgare. Exp Dermatol. 2010; 19(8): 742-50. doi: 10.1111/j.1600-0625.2010.01091.x, PMID: 20482617.

9) Lirdprapamongkol K, Kramb JP, Suthiphongchai T, Surarit R, Srisomsap C, Dannhardt G, et al. Vanillin suppresses metastatic potential of human cancer cells through PI3K inhibition and decreases angiogenesis in vivo. J Agric Food Chem. 2009; 57(8): 3055-63. doi: 10.1021/jf803366f, PMID: 19368348.

10) Strand LP, Scheline RR. The metabolism of vanillin and isovanillin in the rat. Xenobiotica. 1975; 5: 49-63. doi: 10.3109/00498257509056093, PMID: 1154798.

11) Muskiet FAJ, Groen A. Urinary excretion of conjugated homo-vanillic acid, 3,4dihydroxyphenylacetic acid, p-hydroxyphenylacetic acid and vanillic acid by persons on their usual diet and patients with neuroblastoma. Clin Chem. 1979; 25: 1281-4. PMID: 455649.

12) Odink J, Korthals H, Knijff JH. Simultaneous determination of the major acidic metabolites of catecholamines and serotonin in urine by liquid chromatography with electrochemical detection after a onestep sample clean-up on sephadex G-10; influence of vanilla and banana ingestion. J Chromatogr. 1988; 424: 273-83. doi: 10.1016/S0378-4347(00)81104-4, PMID: 2453525.

13) Ozeir M, Muhlenhoff U, Webert H, Lill R, Fontecave M, Pierrel F. Coenzyme Q biosynthesis: Coq6 is required for the C5-hydroxylation reaction and substrate analogs rescue Coq6 deficiency. Chem Biol. 2011; 18: 1134-42. doi: 10.1016/j.chembiol.2011.07.008, PMID: 21944752.

14) Kim SJ, Kim MC, Um JY, Hong SH. Anti-Inflammatory activity of chrysophanol through the suppression of NF-kappaB/caspase-1 activation in vitro and in vivo. Molecules. 2010; 15(9): 7208-17. doi: 10.3390/molecules15107208, PMID: 20959795.

15) Batish DR, Lavanya K, Singh HP, Kohli RK. Root-mediated Allelopathic interference of Nettle-leaved Goosefoot (Chenopodium murale) on wheat (Triticum aestivum). J of Agronomy and Crop Science. 2007; 193(1): 37-44. doi: 10.1111/j.1439-037X.2006.00243.x.

16) Macias FA, Simonet AM, Galindo JCG, Castellano D. Bioactive phenolics and polar compounds from Melilotus messanensis. Phytochemistry. 1999; 50: 35-46.

17) Zhang Z, Liao L, Moore J, Wu T, Wang Z. Antioxidant phenolic compounds from walnut kernels (Juglans regia L.). Food Chem. 2008; 113: 160-5. doi: 10.1016/j.foodchem.2008.07.061.

18) Parveen I, Winters A, Threadgill MD, Hauck B, Morris P. Extraction, structural characterization and evaluation of hydroxycinna of orchard grass (Dactylis glomerata) as substrates for polyphenol oxide. Phytochemistry. 2008; 69: 2799-806. doi: 10.1016/j.phytochem.2008.08.019, PMID: 18929376.

19) Tai A, Sawano T, Ito H. Antioxidative properties of vanillic acid esters in multiple antioxidant assays. Biosci Biotechnol Biochem. 2012; 76(2): 314-8. doi: 10.1271/bbb.110700, PMID: 22313772.

20) Prince PSM, Dhanasekar K, Rajakumar S. Preventive effects of vanillic acid on lipids, bax, bcl-2 and myocardial infarct size on isoproterenol-induced myocardial infarcted rats: a biochemical and in vitro study. Cardiovas Toxicol. 2011; 11(1): 58-66. doi: 10.1007/s12012-010-9098-3, PMID: 21161433.

21) Prince PSM, Rajakumar S, Dhanasekar K. Protective effects of vanillic acid on electrocardiogram, Lipid peroxidation, antioxidants, proinflammatory markers and histopathology in isoprotenol induced cardiotoxic rats. Eur J Pharmacol. 2011; 668(1-2): 233-40. doi: 10.1016/j.ejphar.2011.06.053, PMID: 21763302.

22) Mitchell GF, Jeron A, Koren G. Measurement of heart rate and Q-T interval in the conscious mouse. Am J Physiol. 1998; 274 (3Pt 2): H747-51. PMID: 9530184.

23) Liu Y, Binz J, Numerick MJ, Dennis S, Luo G, Desai B, et al. Hepatoprotection by the farnesoid X receptor agonist GW4064 in rat models of intra- and extrahepatic cholestasis. J Clin Invest. 2003; 112(11): 1678-87. doi: 10.1172/JCI18945, PMID: 14623915, PMCID: PMC281645.

24) Lee RF, Glenn TK, Lee SS. Cardiac dysfunction in cirrhosis. Best Pract Res Clin Gastroenterol. 2007; 21(1): 40-125. doi: 10.1016/j.bpg.2006.06.003, PMID: 17223501.

25) Fadillioglu E, Oztas E, Erdogan H, Yagmurca M, Sogut S, Ucar M, et al. Protective effects of caffeic acid phenethyl ester on doxorubicin-indused cardiotoxicity in rats. J Appl Toxicol. 2004; 24(1): 47-52. doi: 10.1002/jat.945, PMID: 14745846.

26) Ebrahimkhani MR, Moezi L, Kiani S, Merat S, Dehpour AR. Opioid receptor blockade improves mesentric responsiveness in billiary cirrhosis. Dig Dis Sci. 2008; 53(11): 3007-11. doi: 10.1007/s10620-008-0261-7, PMID: 18465246. 
27) Somova LI. Cardiotonic and antidysrhythmic effects of oleanolic and ursolic acids, methyl maslinate and uvaol. Phytomedicine. 2004; 11(2-3): 121-9. doi: 10.1078/0944-7113-00329, PMID: 15070161.

28) Fernández-Martìnez E, Perez-Alvarez V, Tsutsumi V, Shibayama M, Muriel P. Chronic bile duct obstruction induces changes in plasma and hepatic levels of cytokines and nitric oxide in the rat. Exp Toxicol Pathol. 2006; 58(1): 49-58. doi: 10.1016/j.etp.2006.03.002, PMID: 16617007.

29) Liu Y, Binz J, Numerick MJ, Dennis S, Luo G, Desai B, et al. Hepatoprotection by the farnesoid X receptor agonist GW4064 in rat models of intra- and extrahepatic cholestasis. J Clin Invest. 2003; 112(11): 1678-87. doi: 10.1172/JCI200318945, PMCID: PMC281645.

30) Zambruni A, Trevisani F, Caraceni P, Bernardi M. Cardiac electrophysiological abnormalities in patients with cirrhosis. J Hepatol. 2006; 44(5): 994-1002. doi: 10.1016/j.jhep.2005.10.034, PMID: 16510203.

31) Manthey JA, Perkins-Veazie P. Influences of harvest date and location on the levels of $\beta$-carotene, ascorbic acid, total phenols, the in vitro antioxidant capacity, and phenolic profiles of five commercial varieties of mango (Mangifera indica L.). J Agric Food Chem. 2009; 57(22): 10825-30. doi: 10.1021/jf902606h, PMID: 19919121.

32) Kaese S, Verheule S. Cardiac electrophysiology in mice: a matter of size. Front Physiol. 2012; 345(3): 198 205. doi: 10.3389/fphys.2012.00345, PMID: 22973235, PMCID: PMC3433738.

33) Gorre F, Vandekerckhove H. Beta-blockers: focus on mechanism of action. Which beta-blocker, when and why? Acta cardiol. 2010; 65(5): 565-72. PMID: 21125979.

34) Devasagayam TP, Tilak JC, Boloor KK, Sane KS, Ghaskadbi SS, Lele RD. Free radicals and antioxidants in human health: current status and future prospects. J Assoc Physicians India. 2004; 52: 794-804. PMID: 15909857. 